CARPATHIAN JOURNAL OF FOOD SCIENCE AND TECHNOLOGY

journal homepage: http://chimie-biologie.ubm.ro/carpathian_journal/index.html

\title{
RESPONSES OF DENDRITIC AND NK CELLS AFTER MULTISPECIES PROBIOTIC ADMINISTRATION IN BALB/C MICE
}

\author{
Andy Darma ${ }^{1,2^{*}}$, Azwin Mengindera Putra ${ }^{1}$, Pramira Fitri ${ }^{1}$, Alpha Fardah Athiyyah ${ }^{1}$, Reza \\ Gunadi Ranuh ${ }^{1}$, Subijanto Marto Sudarmo ${ }^{1}$ \\ ${ }^{a}$ Department of Child Health, Dr. Soetomo Hospital, Faculty of Medicine, Universitas Airlangga, Surabaya, \\ Indonesia \\ ${ }^{b} \mathrm{PhD}$ candidate of Faculty of Medicine, Universitas Airlangga, Surabaya, Indonesia \\ *andy.darma@fk.unair.ac.id \\ https://doi.org/10.34302/crpjifst/2019.11.5.4 \\ Article history: \\ Received: \\ 9 March 2019 \\ Accepted: \\ 20 September 2019 \\ Keywords: \\ Probiotics; \\ Prebiotics; \\ Synbiotics; \\ Innate immunity;

\begin{abstract}
Dendritic and Natural killer (NK) cells play important roles in the innate immune response. The administration of probiotics is known to affect the immune response. The study aims to assess the effects of multiple probiotic species on the activities of dendritic and NK cells after gastrointestinal damage induced by bacterial lipopolysaccharide (LPS). Male Balb/c mice $(n=24)$ were randomized into four groups: the K-I group (LPS and probiotics), K-II group (LPS only), K-III group (probiotics only), or K-IV group (no intervention). LPS was produced by Escherichia coli O5:B55 cells, while the probiotics were a combination of Lactobacillus acidophilus PXN 35, L. casei subsp. casei PXN 37, L. rhamnosus PXN 54, L. bulgaricusPXN 39, Bifidobacterium breve PXN 25, B. infantis PXN 27, and Streptococcus thermophilus PXN 66. LPS was administered on day 15, while probiotics were administered for 21 consecutive days. After 21 days, the mice were sacrificed and the numbers of dendritic and NK cells were determined by immunohistochemical staining of the ileum. Comparisons with the independent samples $t$-test showed that as compared to the control group, probiotic administration had significantly increased the numbers of dendritic cells, but not NK cells. Meanwhile, in the presence of LPS, there was a significant difference in the number of dendritic cells between the probiotic-LPS and the LPS only groups, but not NK cells. Multiple probiotic species can regulate the innate immunity response through
\end{abstract} \\ dendritic cells, but not NK cells, in Balb/c mice.
}

\section{Introduction}

Pathogenic bacteria, including those that cause diarrhea, induce the release of various cytokines (Sheil et al., 2006; Kuo, Merhige and Hagey, 2013)2), which will lead to an imbalance in the immune response (Saavedra, 2007). Macrophages are the first line of defense against microbial invasion. Secreted cytokines can recruit polymorphonuclear cells to the area of inflammation in the lamina propria. In the immature phase, dendritic cells are also phagocytes that can process both soluble and particulate antigens. The most significant functions of dendritic cells are the processing and presentation of antigens, especially naive $\mathrm{T}$ cells (Mannon, 2005; Shi et al., 2017). Dendritic cells can recognize antigens by monitoring extracellular areas of the lamina propria, by phagocytosis of apoptotic epithelial cells, or hand interdigitation through tight junctions (to prevent damaging to junction 
integrity) in order to directly recognize antigens in the lumen (Mannon, 2005; Delcenserie et al., 2008).

Natural killer (NK) cells also participate in the innate immune response in the intestinal mucosa and play important roles against bacterial infections. Despite being derived from $\mathrm{T}$ cells as precursors, NK cells do not react to adaptive antigens. Nevertheless, NK cells recognize class I major histocompatibility complex (MHC) molecules through the binding of the surface receptors, which then inhibits the release of perforin and ganzyme proteins. Cells that do not express MHC class I molecules, such as virus-infected or tumor cells, are subjected to the activities of NK cells (Mannon, 2005).

Probiotics are combinations of microorganisms that have demonstrated or thought to have some beneficial effect when consumed (Kearney and Gibbons, 2018), such as reducing the $\mathrm{pH}$ of the intestinal lumen, secretion of antimicrobial peptides, inhibition of bacterial adhesion and invasion of epithelial cells, improving barrier function by increasing mucus production, increasing barrier integrity, and improving immunomodulation of epithelial cells, dendritic cells, monocytes/macrophages, and lymphocytes (B lymphocytes, NK cells, T cells) (Floch and Montrose, 2005; Ng et al., 2009). Studies of mice and humans have confirmed that probiotics can induce an immune response and accelerate the healing of various gastrointestinal disorders both acute and chronic (Isolauri et al., 2001; Marteau et al., 2001; Guarino, Vecchio and Canani, 2009; Ritchie and Romanuk, 2012).

These findings of previous studies present an opportunity to explain the mechanisms of probiotics in the prevention of diarrhea through the role of dendritic and NK cells. The mechanism are further explained through experiments that are designed to analyze the relationship between innate immunity activation, especially dendritic and NK cells, in healthy versus pathogen-exposed mice.

\section{Materials and methods}

\subsection{Animals}

Male Balb/c mice $(n=24 ;$ age, $10-12$ weeks; body weight, 30-40 g) were obtained from the Farma Veterinary Center (Surabaya, Indonesia) and acclimated for 1 week prior to experimentation. The study protocol was approved by the Animal Care and Use Committee of the Veterinary Medicine School of Universitas Airlangga (Surabaya, Indonesia). The mice were fed standard feed with free access to water at all times. After acclimation, the mice were randomly allocated to one of four groups: the K-I group, which received probiotics and lipopolysaccharide (LPS), the KII group, which received LPS only, the K-III group, which received probiotics only, or the K-IV group, which received no intervention. LPS was administered only once on day 15 , while probiotics were administered for 21 consecutive days. Each experimental group consisted of six mice. All mice were examined daily for morbidity and other symptoms of illness, such as reduced activity level, abnormal evacuation, and decreased body weight. At the end of the experiment, the ileum was dissected for analysis.

\subsection{Probiotics and LPS}

The probiotics used in this study contained $1 \times 10^{9}$ colony-forming units of a combination of bacteria Lactobacillus acidophilus PXN 35, L. casei subsp. casei PXN 37, L. rhamnosus PXN 54, L. bulgaricus PXN 39, Bifidobacterium breve PXN 25, B. infantis PXN 27, and Streptococcus thermophilus PXN 66. The probiotics in powder form were dissolving in $1.5 \mathrm{~mL}$ of sterile water and administered to mice in groups K-I and K-III via a gastric tube once daily for 21 consecutive days.

LPS, as a representative bacterial endotoxin, was produced by Escherichia coli O55:B5 cells (L2880; Sigma-Aldrich Corporation, St. Louis, MO, USA). LPS was dissolved in $0.9 \%$ non-pyrogenic sterile $\mathrm{NaCl}$ (10:1 ratio) and administered orally through a gastric tube on day 15 at dose of $250 \mu \mathrm{g} / \mathrm{kg}$ 
body weight. LPS was orally administered via a gastric tube on day 15 of the study to the mice in both groups.

\subsection{Histological analysis and detection of immunoglobulin-producing cells}

On day 22 (at the end of the experiment), the abdomens of Balb/c mice in all groups were opened under ether anesthesia. After cleaning, 10\% formalin buffer solution was used to fix the ileum sections. This process was followed by dehydration, clearing, and embedding. Tissue sections were probed with mouse monoclonal antibodies against follicular dendritic cells (F3803; Sigma-Aldrich Corporation) and NK cells (MA1-70100; Thermo Fisher Scientific, Waltham, MA, USA). The samples were observed under a light microscope (CX21; Olympus, Tokyo, Japan) and photographed with an ILCE6000 camera (Sony, Tokyo, Japan). The number of immunopositive cells was determined by counting the mean number of cells in 20 random fields at $450 \times$ magnification. The results are expressed as the number of cells in fields of vision.

\subsection{Statistical analysis}

Differences between groups were analyzed with the independent sample $t$-test for normally distributed data or the Mann-Whitney test for abnormally distributed data. A probability $(p)$ value of $<0.05$ was considered statistically significant

\section{Results and discussions}

The aim of this study was to analyze ability of probiotics to modulate the mouse immune responses, as represented by dendritic and NK cells, in response to exposure to LPS. The mean values of dendritic and NK cell counts for each group are presented in Figure 1 and the baseline characteristic has shown on table 1.
Table 1. Baseline characteristic

\begin{tabular}{|l|l|l|}
\hline \multicolumn{1}{|c|}{ GROUP } & WEIGHT(G) & \multicolumn{1}{|c|}{ AGE(W) } \\
\hline $\begin{array}{c}\text { N=6 Mean } \\
\pm 6 S D\end{array}$ & $\begin{array}{c}\text { N=6 Mean } \\
\pm 6 S D\end{array}$ \\
\hline $\begin{array}{l}\text { 1 (probiotic } \\
+ \text { LPS) }\end{array}$ & $31,61 \pm 1,59$ & $11,50 \pm 0,83$ \\
\hline 2 (LPS) & $33,92 \pm 3,27$ & $10,66 \pm 0,81$ \\
\hline 3(Probiotic) & $31,61 \pm 1,59$ & $11,00 \pm 082$ \\
\hline 4 (none) & $32,73 \pm 2,75$ & $10,83 \pm 0,75$ \\
\hline Total & $32,46 \pm 2,18$ & $10,99 \pm 0,80$ \\
\hline
\end{tabular}

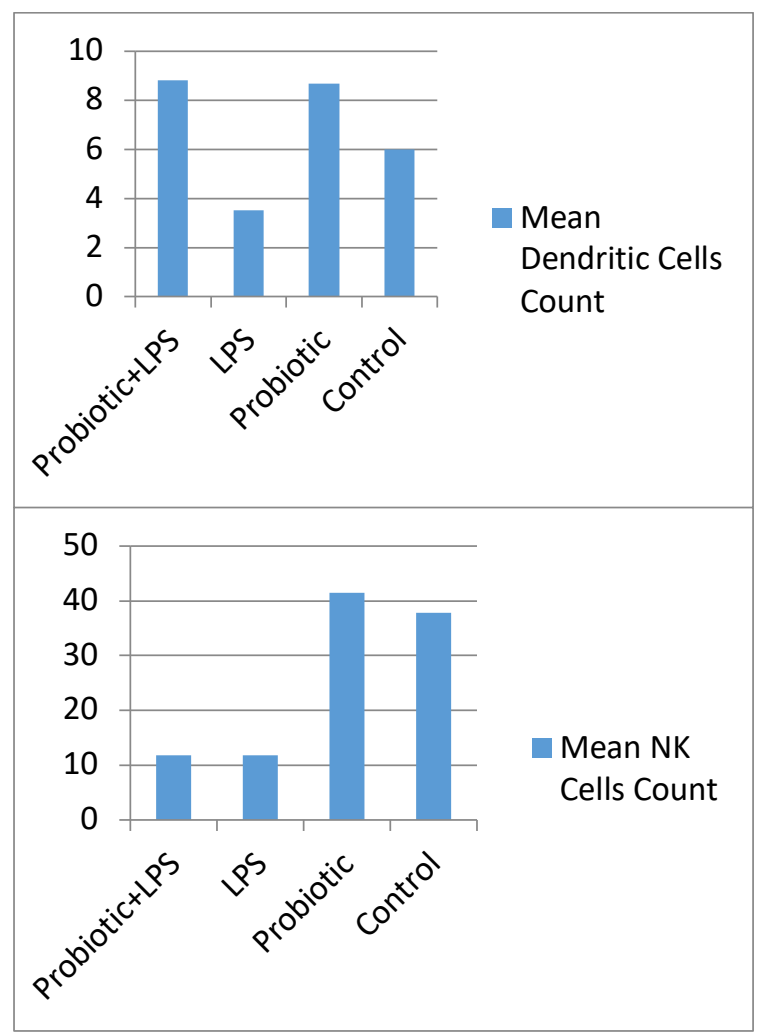

Figure 1. Mean numbers of (a) dendritic cells and (b) NK cells.

The numbers of both dendritic and NK cells were normally distributed; therefore, the independent sample t-test was performed to compare cell counts between the probiotic and control (no treatment) groups. The results revealed significant differences in the numbers of dendritic cell, but not NK cells, between the groups 
Table 2. Comparisons of dendritic and NK cell counts in the probiotic and control groups

\begin{tabular}{|l|c|c|c|c|c|}
\hline \multirow{2}{*}{$\begin{array}{c}\text { Variab } \\
\text { les }\end{array}$} & \multicolumn{2}{|c|}{ Probiotic } & \multicolumn{2}{c|}{ Control } & \multirow{2}{*}{} \\
\cline { 2 - 5 } & $\mathbf{n}$ & $\begin{array}{c}\text { Mean } \\
\text { (SD) }\end{array}$ & $\mathbf{n}$ & $\begin{array}{c}\text { Mean } \\
\text { (SD) }\end{array}$ & \\
\hline $\begin{array}{l}\text { Dendrit } \\
\text { ic cells }\end{array}$ & 6 & $\begin{array}{c}8.67 \\
(2.07)\end{array}$ & 6 & $6(1.41)$ & $\begin{array}{c}0.02 \\
6\end{array}$ \\
\hline $\begin{array}{l}\text { NK } \\
\text { cells }\end{array}$ & 6 & $\begin{array}{c}41.5 \\
(13.23)\end{array}$ & 6 & 37.83 & 0.72 \\
$(20.87)$ & 4 \\
\hline
\end{tabular}

The results of the independent sample t-test between the probiotic-LPS (probiotics for 21 consecutive days and LPS on day 15) and LPS groups revealed significant differences in the numbers of dendritic cells, but not NK cells.

Table 3. Comparison between dendritic and NK cell counts of the probiotic+LPS and LPS

\begin{tabular}{|l|c|c|c|c|c|}
\multicolumn{7}{|c|}{$\begin{array}{c}\text { Varia } \\
\text { bles }\end{array}$} & \multicolumn{2}{|c|}{$\begin{array}{c}\text { Probiotic- } \\
\text { LPS }\end{array}$} & \multicolumn{2}{|c|}{ LPS } & \multirow{2}{*}{} \\
\cline { 2 - 5 } & $\mathbf{n}$ & $\begin{array}{c}\text { Mean } \\
\text { (SD) }\end{array}$ & $\mathbf{n}$ & $\begin{array}{c}\text { Mean } \\
\text { (SD) }\end{array}$ & \\
\hline $\begin{array}{l}\text { Dendr } \\
\text { itic }\end{array}$ & 6 & $\begin{array}{c}8.83 \\
(1.72)\end{array}$ & 6 & $3.5(1.05)$ & 0.000 \\
\hline NK & 6 & $\begin{array}{c}11.83 \\
(3.82)\end{array}$ & 6 & $\begin{array}{c}11.83 \\
(9.67)\end{array}$ & 1.000 \\
cell & & & \\
\hline
\end{tabular}

\subsection{Effects of Probiotics on Innate Immunity}

Defense of the intestinal mucosa involves a combination of immunological and nonimmunological processes, both of which can strengthen resistance of the intestinal mucosa (Blum and Schiffrin, 2003). Probiotic-induced enhancement of the immune system has been confirmed by evidence-based studies (Saavedra, 2007; Shi et al., 2017). Various studies of probiotics mention the benefits of modulating the immune system both in vitro and in vivo (Cross et al., 2004).

\subsection{Effects of Probiotics on Dendritic Cells}

The innate immune status of the probiotic group, as determined by the number of dendritic cells, was significantly increased, as compared to that of the control group, demonstrating that the administration of probiotics improves the innate immune response. Therefore, it can be concluded that defense mechanisms and the immune response were improved in the probiotic-treated intestinal mucosa, as compared to non-treated controls. This finding is consistent with the theory that synbiotics stimulate both the innate and adaptive immune responses in the mucosa (Saavedra, 2007). Communication occurs between probiotic bacteria as normal flora and the host's immune system (Corthésy, Gaskins and Mercenier, 2007; Barzegari et al., 2014). Probiotics are potential immunomodulators that increase the amount and intensify the maturation of dendritic cells in the form of antigen-presenting cells (Mohamadzadeh et al., 2005), which can recognize pathogenassociated molecular patterns through toll-like receptors (TLRs) (Corthésy, Gaskins and Mercenier, 2007). Therefore, dendritic cells have the capacity to "drive" a $\mathrm{T}$ cell subset based on intestinal microflora composition (Christensen, Frøkiær and Pestka, 2002) of both normal and pathogenic microflora (Foligne, 2007).

In this study, there were significantly increased numbers of dendritic cells in the probiotic-LPS group, as compared to the LPSonly group. Past studies have reported that the increased immunological resistance of the host fights against diarrhea-causing pathogens. This concept is considered more reasonable, considering that the main target is to improve the immune response in the mucosa. Also, several randomized controlled studies and meta-analysis have found that the administration of probiotics can effectively prevent gastroenteritis (Guarino, Vecchio and Canani, 2009).

LPS administration will induce an inflammatory response in healthy mice, as demonstrated by the upregulated responses of factors of the innate and adaptive immune systems. Since probiotic exposure, which can increase activation and the number of dendritic cells through TLR-2 expression, was absent 
(Dogi, Galdeano and Perdigón, 2008) in the LPS-only group, a lower number of dendritic cells was obtained. In this group, there was also a decrease in TLR-4 expression caused by CD14 deficiency, so that the immunological process was leaning toward $\mathrm{TH} 2$ cells and there was a disruption of stimulation of TLR-4 expression, which inhibited dendritic cell activation (Mohamadzadeh et al., 2005; Dogi, Galdeano and Perdigón, 2008). In contrast, mice that were first administered probiotics had statistically significant higher numbers of dendritic cells, as compared to the LPS-only group, which further reinforces the theory that probiotics have anti-inflammatory activities. The most marked anti-inflammatory effect was shown by bifidobacterial species, which upregulated interleukin (IL)-10 production by dendritic cells and decreased expression of the costimulatory molecules CD80 and CD40. These effects of probiotic bacteria on dendritic cells may underlie their anti-inflammatory activities.

\section{Effects of Probiotics on NK Cells}

No previous study has used NK cells to evaluate the status of innate immunity. NK cells are natural defensive components against viral infections and tumor cells (Delves et al., 2006). Increased NK cell activity is thought to be part of the capability of the immune response to inhibit malignancy. Upon activation, NK cells respond to bacterial infection in two ways: first, by removing perforin and granzyme enzymes, which induce the apoptosis of infected cells, and, second, by producing interferon (IFN) $-\gamma$, which activates macrophages and increases the ability to kill and devour bacteria. Macrophages release IL12, a potent cytokine that re-activates NK cells (Abbas, Lichtman and Pillai, 2012; Baratawidjaja and Rengganis, 2009).

Many studies have revealed that the administration of probiotic bacteria will affect the overall nonspecific immune response by increasing pathogen phagocytosis through increased macrophage activation and subsequent cytokine production (Erickson and
Hubbard, 2000). Another study of 50 adults found that the addition of the probiotic B. lactis HN019 to milk could increase the activities of polymorphonuclear cells and NK cells, as compared to the control group (Chiang et al., 2000). Similarly, another study found that the administration of Lactobacillus casei ssp. with dextran significantly increased the activities of $\mathrm{NK}$ cells in the spleen of Balb/c mice (Ogawa et al., 2005). Also, the addition of the probiotics L. gasseri and L. coryniformis to yogurt had significantly increased the number of NK cells in the blood of healthy adults by $21 \%$ (Olivares et al., 2006). This is in line with the results of a present study of an increase in the number of NK cells, although this increase was not significant. However, another study of 20 healthy young female subjects reported that the consumption of L. casei Shirota fermented milk for 4 weeks had no influence NK cell activity (Spanhaak, Havenaar and Schaafsma, 1998). Therefore, further studies are needed to determine the most effective strains and doses of probiotics for the stimulation of NK cells.

The results of the in vivo study showed that the number of NK cells in the innate cell immune was decreased after the administration of LPS. Different results were obtained in another study that found that LPS can stimulate NK cell proliferation, secrete IFN- $\gamma$, and increase toxicity of NK cells to in vitro target cells in human blood (Nedvetzki et al., 2007). This difference can explained by the differences in observation methods (in vivo vs. in vitro). The decrease in NK cell number and activities in the in vivo studies can occur due to natural microbiota in the intestine that act as probiotics.

Probiotic administration increases the activity and production of NK cells, which are cytotoxic lymphocytes, the main component of the innate immune system, are increased in number along with increased production of IL12. This finding is in line with the results of previous studies, which stated that administration of probiotics could increase the numbers of cells expressing IL-1, IL-2, and IL12. IL-12 and IL-18 are produced by Th1 and 
NK cells and act as synergistic stimulators of IFN- $\gamma$ and enforce the probiotic response toward mononuclear cells. LPS will increase the activities of NK cells through mechanisms that involve IFN- $\gamma$. Hence, NK cells become more efficient and toxic (Salata et al., 1984). However, in our in vivo study, the number of NK cells had continued to decrease after LPS exposure, even though probiotics were administered beforehand. The NK cell count did not significantly differ between the probiotic-LPS and LPS-only groups.

\section{Conclusions}

The results of this study showed that multiple probiotic species can regulate the innate immune response through dendritic cells, but not NK cells, in Balb/c mice.

\section{References}

Abbas AK, Lichtman AH, Pillai S. (2012). Cellular and molecular immunology. Saunders Elsevier; pp. 566.

Baratawidjaja K, Rengganis I. (2009). Imunologi Dasar. 8th ed. Jakarta: Balai Penerbit Fakultas Kedokteran Indonesia.

Barzegari, A. et al. (2014). Imposition of encapsulated non-indigenous probiotics into intestine may disturb human core microbiome. Frontiers in Microbiology, 5(393). doi: 10.3389/fmicb.2014.00393.

Blum, S. and Schiffrin, E. J. (2003). Intestinal microflora and homeostasis of the mucosal immune response: implications for probiotic bacteria?. Current issues in intestinal microbiology, 4(2), pp. 53-60. Available at: http://www.ncbi.nlm.nih.gov/pubmed/1450 3689.

Chiang, B. et al. (2000). Enhancing immunity by dietary consumption of a probiotic lactic acid bacterium (Bifidobacterium lactis HN019): optimization and definition of cellular immune responses. European Journal of Clinical Nutrition, 54(11), pp. 849-855. doi: 10.1038/sj.ejcn.1601093.

Christensen, H. R., Frøkiær, H. and Pestka, J. J. (2002). Lactobacilli Differentially
Modulate Expression of Cytokines and Maturation Surface Markers in Murine Dendritic Cells. The Journal of Immunology. doi: 10.4049/jimmunol.168.1.171.

Corthésy, B., Gaskins, H. R. and Mercenier, A. (2007). Cross-Talk between Probiotic Bacteria and the Host Immune System. The Journal of Nutrition, 137(3), pp. 781S790S. doi: 10.1093/jn/137.3.781S.

Cross, M. L. et al. (2004). Patterns of cytokine induction by gram-positive and gramnegative probiotic bacteria. FEMS Immunology \& Medical Microbiology, 42(2), pp. 173-180. doi: 10.1016/j.femsim.2004.04.001.

Delcenserie, V. et al. (2008). Immunomodulatory effects of probiotics in the intestinal tract. Current issues in molecular biology, 10(1-2), pp. 37-54. Available at: http://www.ncbi.nlm.nih.gov/pubmed/1852 5105.

Delves PJ, Martin SJ, Burton DR, Roitt IM. (2017). Essential immunology. John Wiley \& Sons; pp. 556.

Dogi, C. A., Galdeano, C. M. and Perdigón, G. (2008). Gut immune stimulation by non pathogenic Gram $(+)$ and Gram( $(-)$ bacteria. Comparison with a probiotic strain. Cytokine, 41(3), pp. 223-231. doi: 10.1016/j.cyto.2007.11.014.

Erickson, K. L. and Hubbard, N. E. (2000). Probiotic Immunomodulation in Health and Disease. The Journal of Nutrition, 130(2), pp. 403S-409S. doi: $10.1093 / \mathrm{jn} / 130.2 .403 \mathrm{~S}$.

Floch, M. H. and Montrose, D. C. (2005). Use of probiotics in humans: An analysis of the literature. Gastroenterology Clinics of North America. doi: 10.1016/j.gtc.2005.05.004.

Foligne, B. (2007). Correlation between in vitro and in vivo immunomodulatory properties of lactic acid bacteria. World Journal of Gastroenterology, 13(2), p. 236. doi: 10.3748/wjg.v13.i2.236.

Guarino, A., Vecchio, A. Lo and Canani, R. B. 
(2009). Probiotics as prevention and treatment for diarrhea. Current Opinion in Gastroenterology, 25(1), pp. 18-23. doi: 10.1097/MOG.0b013e32831b4455.

Isolauri, E. et al. (2001). Probiotics: effects on immunity. The American Journal of Clinical Nutrition, 73(2), pp. 444s-450s. doi: 10.1093/ajen/73.2.444s.

Kearney, S. M. and Gibbons, S. M. (2018). Designing synbiotics for improved human health. Microbial Biotechnology. WileyBlackwell, 11(1), pp. 141-144. doi: 10.1111/1751-7915.12885.

Kuo, S.-M., Merhige, P. M. and Hagey, L. R. (2013). The Effect of Dietary Prebiotics and Probiotics on Body Weight, Large Intestine Indices, and Fecal Bile Acid Profile in Wild Type and IL10-/- Mice. PLoS ONE. Edited by H. Smidt, 8(3), p. e60270.

doi:

10.1371/journal.pone.0060270.

Mannon, P. (2005). Normal Gut Mucosal Immunity: A Dynamic Balance of Tolerance and Defense. Gastroenterology \& Hepatology, 1(1), pp. 50-6.

Marteau, P. R. et al. (2001). Protection from gastrointestinal diseases with the use of probiotics. The American Journal of Clinical Nutrition, 73(2), pp. 430s-436s. doi: 10.1093/ajen/73.2.430s.

Mohamadzadeh, M. et al. (2005). Lactobacilli activate human dendritic cells that skew $\mathrm{T}$ cells toward $\mathrm{T}$ helper 1 polarization. Proceedings of the National Academy of Sciences, 102(8), pp. 2880-2885. doi: 10.1073/pnas.0500098102.

Nedvetzki, S. et al. (2007). Reciprocal regulation of human natural killer cells and macrophages associated with distinct immune synapses. Blood, 109(9), pp. 3776-3785. doi: 10.1182/blood-2006-10052977.

$\mathrm{Ng}$, S. C. et al. (2009). Mechanisms of action of probiotics: Recent advances. Inflammatory Bowel Diseases, 15(2), pp. 300-310. doi: 10.1002/ibd.20602.

Ogawa, S. et al. (2005). Molecular Determinants of Crosstalk between
Nuclear Receptors and Toll-like Receptors. Cell, 122(5), pp. 707-721. doi: 10.1016/j.cell.2005.06.029.

Olivares, M. et al. (2006). The consumption of two new probiotic strains, Lactobacillus gasseri CECT 5714 and Lactobacillus coryniformis CECT 5711, boosts the immune system of healthy humans. International microbiology: the official journal of the Spanish Society for Microbiology, 9(1), pp. 47-52. doi: 10.2436/im.v9i1.9548.

Ritchie, M. L. and Romanuk, T. N. (2012). A Meta-Analysis of Probiotic Efficacy for Gastrointestinal Diseases. PLoS ONE. Edited by M. M. Heimesaat, 7(4), p. e34938. doi: 10.1371/journal.pone.0034938.

Saavedra, J. M. (2007). Use of Probiotics in Pediatrics: Rationale, Mechanisms of Action, and Practical Aspects. Nutrition in Clinical Practice, 22(3), pp. 351-365. doi: 10.1177/0115426507022003351.

Salata, R. A. et al. (1984). Augmentation of natural killer cell activity by lipopolysaccharide through separable effects on the binding of nonadherent lymphocytes to tumor targets and tumor killing. Cancer research, 44(3), pp. 1044 7. Available at: http://www.ncbi.nlm.nih.gov/pubmed/6607 107

Sheil, B. et al. (2006). Role of interleukin (IL$10)$ in probiotic-mediated immune modulation: an assessment in wild-type and IL-10 knock-out mice. Clinical and Experimental Immunology, 144(2), pp. 273-280. doi: $10.1111 / \mathrm{j} .1365-$ 2249.2006.03051.x.

Shi, N. et al. (2017). Interaction between the gut microbiome and mucosal immune system. Military Medical Research, 4(1), p. 14. doi: 10.1186/s40779-017-0122-9.

Spanhaak, S., Havenaar, R. and Schaafsma, G. (1998). The effect of consumption of milk fermented by Lactobacillus casei strain Shirota on the intestinal microflora and immune parameters in humans. European 
Journal of Clinical Nutrition, 52(12), pp. 899-907. doi: 10.1038/sj.ejcn.1600663.

\section{Acknowledgment}

The authors sincerely thank the Director of Dr. Soetomo General Hospital for supporting this study and the Dean of the Faculty of Medicine of Airlangga University for allowing the author to finish this doctoral study. 